\title{
KAJIAN KESIAPAN SDM LOGISTIK MENGHADAPI ERA MEA
}

\author{
Fino Wahyudi Abdul, Cundo Harimurti, Resista Vikaliana \\ Program Studi Manajemen Logistik \\ Institut Ilmu Sosial dan Manajemen STIAMI \\ email korespondensi: resistav31@gmail.com/resista@stiami.ac.id
}

\begin{abstract}
Abstrak. Masyarakat Ekonomi Asean (MEA) yang diterapkan pada tahun 2015 merupakan upaya untuk meningkatkan pertumbuhan ekonomi di kawasan Asia Tenggara. Logistik merupakan salah satu sektor integrasi yang prioritas dalam MEA.

Pada sektor layanan logistik, sebagai negara maritim, Indonesia terdiri atas beribu-ribu pulau yang merupakan kesatuan tak terpisahkan. Kondisi ini menjadikan Indonesia sebagai negara yang memiliki transportasi pelabuhan import pada front line dan inter island transportation. Dalam menghadapi MEA, Indonesia dituntut membangun Sistem Logistik Nasional (Sislognas) yang terintegrasi . Menurut Logistics Performance Index World Bank 2010 Indonesia menduduki peringkat 75 dari 183 negara. Sistem logistik di Indonesia masih perlu penanganan yang lebih baik, selain membereskan permasalahan visi dan misi yang belum terintegrasi. Selain infrastruktur, visi dan misi untuk mendukung peningkatan daya saing pelaku bisnis di Indonesia juga belum terintegrasi dan terkoordinasi dengan baik. Sistem tersebut dapat terwujud bila didukung sumber daya manusia yang memiliki pengetahuan logistik. Ketertinggalan SDM Indonesia dalam bidang logistik lebih karena dua faktor, yakni kualitas dan speed. Dengan diterapkannya MEA, maka pemerintah dan pelaku bisnis harus siap dan menghadapinya dengan mempersiapkan strategi bisnis, khususnya menigkatkan SDM pada bidang logistik agar Indonesia mampu bersaing di era ini. Professionalisme manajemen, sistem informasi, budaya, strategi fungsional harus berjalan secara bersamaan untuk mencapai sebuah tujuan perusahaan. Dalam menghadapi tantangan globalisasi perusahaan atau pelaku bisnis, pemerintah dan akademis perlu mengembangkan tenaga kerja nasional seperti meningkatkan mutu kurikulum, maupun pelatihan yang efektif untuk menunjang dan meningkatkan mutu serta motivasi SDM.

Kata Kunci: Sumber Daya Manusia/ SDM, Logistik, Masyarakat Ekonomi Eropa/ MEA
\end{abstract}

Abstract. Asean Economic Community (AEC) implemented in 2015 is an effort to increase economic growth in Southeast Asia. Logistics is one of the priority integration sectors in the $A E C$. In the logistics service sector, as a maritime country, Indonesia consists of thousands of islands which are inseparable unity. This condition makes Indonesia as a country that has import port transportation on front line and inter island transportation. In facing the , Indonesia is required to build an integrated National Logistics System (Sislognas).

According to the Logistics Performance Index of World Bank 2010 Indonesia was ranked 75 out of 183 countries. Logistic system in Indonesia still need better handling, besides settling vision problem and mission which not yet integrated. In addition to infrastructure, vision and mission to support the improvement of business competitiveness in Indonesia is also not well integrated and coordinated. The system can be realized if supported by human resources who have logistics knowledge. Lack of human resources in the field of logistics more due to two factors, namely quality and speed. With the implementation of AEC, the government and business people must be ready and face it by preparing business strategy, especially improving human resources in logistics so that Indonesia can compete in this era. Management professionalism, information systems, culture, functional strategies must run simultaneously to achieve a corporate objective. In facing the challenges of globalization of companies or businesses, government and academia need to develop national workforce such 
Fino Wahyudi Abdul, Cundo Harimurti, Resista Vikaliana Kajian Kesiapan SDM Logistik Menghadapi Era MEA...

as improving the quality of curriculum, as well as effective training to support and improve the quality and motivation of human resources.

Key words: Human Resources Management, Logistics Asean Economic Community/ AEC

\section{PENDAHULUAN}

Kesepakatan MEA (Masyarakat Ekonomi ASEAN) dicanangkan pada KTT ASEAN yang ke-12 di bulan Januari 2007, para pemimpin mulai menegaskan komitmen mereka tentang melakukan percepatan pembentukan komunitas ASEAN di tahun 2015 yang telah diusulkan oleh ASEAN Vision 2020 dan ASEAN Concord II, dan adanya penandatanganan deklarasi CEBU mengenai percepatan pembentukan komunitas ekonomi ASEAN di tahun 2015 dan untuk melakukan pengubahan ASEAN menjadi suatu daerah perdagangan yang bebas barang, investasi, tenaga kerja terampil, jasa dan aliran modal yang lebih bebas lagi.

MEA atau Masyarakat Ekonomi ASEAN ialah suatu realisasi dari tujuan akhir terhadap integrasi ekonomi yang telah dianut didalam ASEAN Visi 2020 yang berdasarkan atas konvergensi kepentingan para negara-negara anggota ASEAN untuk dapat memperluas dan memperdalam integrasi ekonomi lewat inisiatif yang ada dan baru dengan memiliki batas waktu yang jelas. Di dalam mendirikan masyarakat ekonomi ASEAN atau MEA, ASEAN mesti melakukan tidakan sesuai dengan pada prinsip-prinsip terbuka, berorientasi untuk mengarah ke luar, terbuka, dan mengarah pada pasar ekonomi yang teguh pendirian dengan peraturan multilateral serta patuh terhadap sistem untuk pelaksanaan dan kepatuhan komitmen ekonomi yang efektif berdasarkan aturan.

Ada dua belas sektor integrasi yang diprioritaskan dalam MEA. Sektor-sektor tersebut adalah agro-based product, air travel, automotive, e-asean, electronics, fisheries, healthcare, rubber-based products, textile and apparels, tourism, wood-based products dan logistics services.
Pada sektor layanan logistik, sebagai negara maritim, Indonesia terdiri atas beribu-ribu pulau yang merupakan kesatuan tak terpisahkan. Kondisi ini menjadikan Indonesia sebagai negara yang memiliki transportasi pelabuhan import pada front line dan inter island transportation. Dalam menghadapi MEA, Indonesia dituntut membangun Sistem Logistik Nasional (Sislognas) yang terintegrasi .

Menurut Logistics Performance Index World Bank 2010 Indonesia menduduki peringkat 75 dari 183 negara. Kondisi infrastruktur logistik Indonesia masih belum baik dengan cost logistics 20-25\% dari GDP Indonesia. Pertumbuhan bisnis logistik di Indonesia sekitar $15 \%$ per tahun. Sistem logistik yang memiliki kualitas dan kuantitas memadai serta sudah terintegrasi akan membangkitkan iklim bisnis. Hal itu akan mendorong lancaranya pergerakan barang, dengan biaya yang efisien dan pada akhirnya meningkatkan perekonomian.

Sistem logistik di Indonesia masih perlu penanganan yang lebih baik, selain membereskan permasalahan visi dan misi yang belum terintegrasi. Selain infrastruktur, visi dan misi untuk mendukung peningkatan daya saing pelaku bisnis di Indonesia juga belum terintegrasi dan terkoordinasi dengan baik.

Sistem tersebut dapat terwujud bila didukung sumber daya manusia yang memiliki pengetahuan logistik. Ketertinggalan SDM Indonesia dalam bidang logistik lebih karena dua faktor, yakni kualitas dan speed. Sumber daya manusia yang bekerja pada bidang logistik umumnya karena kebutuhan perusahaan dan bukan karena membangun kompetensinya dari awal. Profesi di bidang logistik belum populer bagi dunia 
Majalah Ilmiah Institut STIAMI

ISSN 2579-8952

pendidikan dan pencari kerja baru. Kesenjangan yang cukup lebar antara program pendidikan dan pelatihan yang ada pada institusi perguruan tinggi dengan dunia usaha yang membutuhkan.

\section{PERMASALAHAN}

Bagaimana meningkatkan kompetensi SDM logistik dalam MEA?

\section{TINJAUAN PUSTAKA}

\section{Perubahan Lingkungan Manajemen SDM}

Manajemen SDM menurut Hasibuan (2012) adalah ilmu dan seni mengatur dan peran hubungan kerja agar dapat secara efektif dan efisien dalam rangka membantu mewujudkan tujuan perusahaan, karyawan dan masyarakat.

Beberapa parameter kebijakan HRM lainnya juga merupakan elemen utama dari improvisasi logistik dan manajemen rantai pasokan. Manajemen Sumber Daya Manusia merupakan elemen kunci untuk keberhasilan tujuan organisasi (Anastasiou, 2012). Dalam hal ini, manajemen sumber daya manusia modern harus secara proaktif diterapkan pada rantai pasokan perusahaan (Wellins dan Rioux, 2000).

Tanggung jawab departemen SDM secara bertahap akan menjadi lebih luas dan strategi dari kalangan orang - orang bisnis mulai memasukkan "departemen personalia" dalam diagram perusahaan mereka. Saat ini, globalisasi di bidang ekonomi dan beberapa tren lainnya merupakan pemicu perubahaan bagi perusahaan dalam mengorganisasikannya, mengelola, dan memanfaatkan departemen personalia/SDM mereka.

1. a)Lingkungan yang Berubah

Globalisasi mengacu pada perusahaan untuk memperluas, kepemilikan, penjualan, dan manufaktur mereka ke pasar baru di luar negeri. Globalisasi yang meluas berarti perusahaan akan siap untuk meningkatkan pesaing dan dengan seiringnya meningkat pesaing, maka akan memicu perusahaan tersebut menjadi perusahaan kelas dunia untuk menekankan biaya, untuk membuat karyawan lebih produktif, serta menemukan berbagai hal yang baik untuk dilakukan dan tidak terlalu mahal.

\section{1. b)Kemajuan Teknologis}

Banyak pula perusahaan kelas dunia yang meningkat di karenakan teknologi yang dimilikinya. Banyak pula contoh perusahaan yang melakukan hal tersebut, sehingga saat ini SDM di tuntut untuk menghadapi tantangan dengan menerapkan teknologi dengan segera dalam mengerjakan tugastugas yang dapat meningkatkan kegiatan operasi mereka.

1. c)Mengekspor Pekerjaan

Tekanan persaingan dan pencarian efesien yang lebih baik juga mendesak para pemilik perusahaan untuk mengekspor pekerjaan keluar negeri. Dikarenakan hal ini dapat membantu perusahaan untuk membuka cabang di luar negeri.

1. d)Sifat Pekerjaan

Dengan persaingan global, lebih banyak pekerjaan manufaktur berpindah ke negara lain dengan upah tenaga kerja yang murah da itu kini menjadi tren di beberapa perusahaan. Modal yang harus di keluarkan SDM mengacu pada pendidikan, pelatihan, pengetahuan, keterampilan, dan keahlian. Dengan lingkungan yang ada pada era globalisaisi ini, para manajer pun membutuhkan sistem SDM baru yang berstandar kelas dunia dan keahlian untuk memilih, melatih, memotivasi para karyawan, dan untuk mendapatkan komitmen mereka untuk lebih berperan sebagai rekan.

1. e) Demografis Tenaga Kerja

Pada saat yang sama demografis juga akan berubah. Salah satunya para pekerja yang semakin tua, sehingga perusahaan mengalami kekurangan tenaga professional yang berat dan membutuhkan SDM yang baru. Perusahaan dituntut untuk tepat dalam memilihnya dan dapat menjadikan para SDM yang bisa dihandalkan untuk mencapai tujuan perusahaan bersama. Banyak pula perusahaan yang tetap menggunakan karyawan yang lebih tua dikarenakan 
Fino Wahyudi Abdul, Cundo Harimurti, Resista Vikaliana Kajian Kesiapan SDM Logistik Menghadapi Era MEA...

karyawan itu lebih

pengalaman/profesional.

\section{Mengukur Konstribusi SDM}

Tugas - tugas dan prioritas SDM berkembang dari waktu ke waktu dikarenakan mereka harus menyesuaikan dalam mengarahkan strategi perusahaan. Tren seperti globalisasi dan meningkatkan persaingan telah menempatkan SDM pada barisan depan dan posisi kunci dalam kebanyakan usaha dalam perencanaan strategi. Semua manajer dan SDM harus lebih mengekspresikan rencana departemen mereka dan menyelesaikannya dengan istiah yang mengukur. Manajemen puncak ingin melihat para manajer dalam membuat rencana perusahaan yang lebih bernilai, contohnya dengan meningkatkan semangat kerja, sehingga dapat meningkatkkan pula prestasinya. Beberapa cara dalam mengukur standar kontribusi SDM:

1) Penekanan pada prestasi

2) Standar Pengukuran

3) Kartu nilai SDM

4) Sistem Tenaga Kerja

Empat faktor yang dapat dilakukan manajemen perusahaan untuk meningkatkan SDM Logistik di Indonesia, di antaranya:

1. Acceptance and Understanding of Supply Chain Requirement in Global Context.

2. Perusahaan sebaiknya mengerti kebutuhan logistik yang diperlukan. Hal itu dilakukan dengan cara mengetahui faktor keuangan seperti cash flow management dan marketing

adventage, untuk mengetahui keuntungan penjualan, serta tidak kalah penting adalah customer satisfaction.

2. Technology.Perkembangansocial media yang semakin mewabah seharusnya bisa menjadi sarana yang efektif untuk meningkatkan wawasan karyawan dan menumbuhkan kreativitas bisnis.
3. Supply Chain Process.Tentunya kita perlu mengetahui proses alur kerja dari industri itu sendiri. Kelemahan manajemen seperti infrastruktur, transportasi harus segera ditangani agar penerimaan barang bisa berjalan tepat waktu.

4. Executive and Managerial Talents.Hal paling mendasar dalam meningkatkan mutu SDM di Indonesia adalah kompetensinya.

\section{PEMBAHASAN}

Tantangan SDM Logistik saat ini adalah peningkatan jumlah tenaga kerja di bidang logistik dan peningkatan kualitas dan kompetensi sumber daya yang ada. Indonesia masih dihadapkan pada kelangkaan tenaga ahli, spesialis, dan profesional dalam bidang logistik baik pada level manajerial maupun operasional. Selain itu sumber daya manusia yang adapun masih memiliki kompetensi yang rendah.

Peluang profesi logistik di Indonesia adalah:

Tingginya permintaan akan tenaga ahli logistik

Institusi pendidikan logistik mulai bermunculan

Kompleksitas sistem logistik di Indonesia Paradigma baru dalam logistik dan supply chain di duia (custumer dan IT)

Logistik merupakan layanan atau berbasis manusia

Indonesia dapat menjadi center of economic di Asia Tenggara

Untuk mencapai daya saing yang tangguh di bidang logistik, tentunya perlu didukung oleh SDM logistik yang memiliki kompetensi, profesional yang terpercaya baik pada tingkat operasional, manajerial dan strategis, dan mencukupi kebutuhan nasional untuk mewujudkan efisiensi dan efektifitas kinerja sistem logistik nasional itu sendiri. Dukungan SDM yang seperti itu dapat tercapai dengan menempuh langkahlangkah strategis sebagai berikut: 


\section{Majalah Ilmiah Institut STIAMI}

ISSN 2579-8952

1. Penataan keilmuan, keahlian dan profesi logistik melalui pengkuan dan penetapan Logistik sebagai suatu bidang keilmuan dan keahlian (profesi) yang dibutuhkan, diselenggarakan dan dikembangkan secara formal di Indonesia, dan penyusunan klasifikasi dan jenjang kompetensi dan profesi logistik, serta penataan sistem pendidikan dan pelatihan profesi logistik nasional.

2. Penyelenggaraan pendidikan dan pelatihan profesional di bidang logistik melalui penyelenggaraan pendidikan dan pelatihan kompetensi profesi logistik baik untuk aparatur pemerintah maupun Pelaku dan Penyedia Jasa Logistik, dan pemberian insentif dan mendorong aparatur pemerintah maupun Pelaku dan Penyedia Jasa Logistik untuk mendapatkan sertifikasi internasional.

3. Pengembangan institusi pendidikan dan pelatihan profesional di bidang logistik melalui pendirian program studi logistik baik yang berorientasi keilmuan maupun terapan, pengembangan lembaga akreditasi dan sertifikasi profesi logistik, pendirian lembaga pelatihan profesional di bidang logistik, peningkatan dukungan pemerintah dalam pengembangkan institusi pendidikan dan pelatihan, serta mengembangkan dan meningkatkan jejaring kerjasama antara lembaga pendidikan dan pelatihan pemerintah dan swasta, dan kerjasama dengan mitra luar negeri.

4. Pengembangan sarana dan prasarana pendidikan dan pelatihan logistik bertaraf internasional melalui pembangunan sarana dan prasarana pendidikan jalur akademik bertaraf internasional, dan pembangunan sarana dan prasarana pendidikan jalur terapan bertaraf internasional.

Selain itu, konsep pengembangan SDM logistik nasional dapat :
- Menerapkan sistem sertifikasi logistik nasional yang meliputi semua level (operasional, manajerial dan eksekutif). Hal ini untuk mengurangi ketergantungan terhadap sertifikasi internasional dengan memasukkan beberapa faktor yang menjadi ciri khas Indonesia.

- Sinergi dan kolaborasi antara pemerintah, akademis dan pengusaha diperlukan dalam membangun SDM logistik nasional. BNSP (Badan Nasional Sertifikasi Profesi) juga dilibatkan dalam pembentukan SDM Logistik.

- Izin usaha logistik dikatikan dengan sertifikasi logistik nasional di bidang SDM

- Insentif bagi perusahaan yang memberikan pelatihan logistik bagi karyawannya.

- Dibuka jurusan logistik mulai dari tingkat SMK, D3, S1, S2 hingga S3 dengan dukungan Kementerian Pendidikan.

Dalam memasuki era globalisasi ini, pemerintah harus lebih serius memikirkan dan bertindak untuk menghadapinya. Bukan hanya pemerintah saja, namun pelaku bisnis dalam perusahaan juga harus lebih pintar dan kreatif dalam mengelola perusahaannya agar mampu bersaing dalam pasar bebas Asia saat ini dan ke depannya. Jika tidak segera ditindak maka yang akan terjadi adalah adanya gejala menjual diri bangsa dengan hanya mengandalkan SDA yang tak terolah dan tenaga buruh atau SDM yang murah dan akan mengakibatkan kesenjangan ekonomi

\section{Kesimpulan}

Kondisi SDM Logistik Indonesia masih belum memiliki kuantitas dan kualitas yang memadai untuk memenuhi kebutuhan tenaga logistik di Indonesia. Liberasiasi Logistik pada MEA, perlu diambil langkah cepat dan tepat dalam meningkatkan profesionalisme SDM Logistik.. Upaya yang diperlukan adalah sinergi dan kolaborasi antara pemerintah, akademisi dan pengusaha 
Fino Wahyudi Abdul, Cundo Harimurti, Resista Vikaliana Kajian Kesiapan SDM Logistik Menghadapi Era MEA...

Dengan diterapkannya MEA saat ini, maka pemerintah dan pelaku bisnis harus siap dan menghadapinya dengan mempersiapkan strategi bisnis, khususnya menigkatkan SDM pada bidang logistik agar Indonesia mampu bersaing di era ini. Professionalisme manajemen, sistem informasi, budaya, strategi fungsional harus berjalan secara bersamaan untuk mencapai sebuah tujuan perusahaan. Dalam menghadapi tantangan globalisasi perusahaan atau pelaku bisnis, pemerintah dan akademis perlu mengembangkan tenaga kerja nasional seperti meningkatkan mutu kurikulum, maupun pelatihan yang efektif untuk menunjang dan meningkatkan mutu serta motivasi SDM.

\section{Daftar Pustaka}

Anastasiou, Sophia. 2012. Critical human resources management functions for efficient logistics and supply chain management Proceeding in The2nd International Conference on Supply Chains

Hasibuan, Malayu. 2012. Manajemen Sumber Daya Manusia. Jakarta: PT Bumi. Aksara

Wellins, R., and Rioux, S. 2000. The growing pains of globalizing HR, Training and Development, May

Sumber Internet:

http://www.rantaipasok.com/2012/12/kua

litas-sdm-logistik-indonesia-masih.html http://portalhr.com/peoplemanagement/resourcing/4-pr-bagi-sdmlogistik-indonesia/

https://networkids.wordpress.com/2015/01 121/strategi-meningkatkan-kwalitas-sdmdalam-menghadapi-era-globalisasi-padabidang-logistik/ http://topcoachindonesia.com/mea-tuntutkesiapan-sdm-di-bidang-logistik/ 